\title{
Google Sites como herramienta didáctica online en el aprendizaje significativo del área de ciencia, tecnología y ambiente en estudiantes de cuarto grado de educación secundaria
}

\section{Google Sites as an online teaching tool for meaningful learning in the area of science, technology and environment in fourth grade students of secondary education}

Oscar Melanio Dávila Rojas ${ }^{1}$

https://orcid.org/0000-0001-6915-8373

Carmen Rosa Gutiérrez Pantoja ${ }^{2}$

https://orcid.org/0000-0001-9817-9405

Universidad Católica Sedes Sapientiae, Perú

Recibido: 05-01-2019

Aceptado: 21-03-2019

\section{Cita Recomendada}

Dávila, O. \& Gutiérrez, C. (2019). Google Sites como herramienta didáctica online en el aprendizaje significativo del área de Ciencia, Tecnología y Ambiente en estudiantes de cuarto grado de Educación Secundaria. Hamut'ay, 6(1), 33-53.

http://dx.doi.org/10.21503/hamu.v6i1.1573

\section{RESUMEN}

Esta investigación abordó la importancia del Google Sites como herramienta didáctica online. Buscó respuesta a la pregunta: ¿Cuál es la influencia del Google Sites como herramienta didáctica online en el aprendizaje significativo en el área de Ciencia, Tecnología y Ambiente, en estudiantes del cuarto grado del nivel secundaria de la Institución Educativa Publica No 3056 "Gran Bretaña" Lima, 2017? Como respuesta a dicha pregunta, se planteó la hipótesis de que Google Sites como herramienta didáctica online influye significativamente en el aprendizaje significativo. El trabajo se desarrolló con un enfoque cuantitativo, de alcance explicativo y diseńo cuasi-experimental, modelo pre test - post test, con dos grupos: uno experimental y otro de control. Se ejecutó en una muestra no probabilística de 46 estudiantes (22 del grupo de control y 24 del grupo experimental). El instrumento utilizado fue la prueba diagnóstica regional 2017 para el área de CTA utilizada por el Ministerio de Educación de Perú para evaluar a estudiantes del cuarto grado de educación secundaria. Los resultados del contraste permitieron verificar la hipótesis planteada, con un nivel de significancia $\operatorname{de} p=, 000<, 001$.

Palabras Clave: Google Sites, herramienta tecnológica, portafolio, archivador digital, blog, web, Ciencia, Tecnología.

\footnotetext{
1 Doctor en Ciencias de la Educación por la Universidad Nacional de Educación Enrique Guzmán y Valle, Magíster en Docencia y Gestión Educativa en la Universidad César Vallejo, Licenciado en Lengua y Literatura en la Universidad Nacional Federico Villarreal, Abogado titulado por la Universidad Nacional Mayor de San Marcos, Docente-Investigador especialista en Metodología de la Investigación. E-mail: oscarmelanio@yahoo.es

2 Licenciada en Educación, con especialidad en Biología - Química por la Universidad Nacional Mayor de San Marcos, con estudios concluidos en Maestría por la Universidad Católica Sedes Sapientiae y Especialización en Educación y Tecnologías de la Información y Comunicación (TIC) por la Universidad Antonio Ruiz de Montoya. E-mail: gutierrezcarmen45@gmail.com
} 


\section{Abstract}

This research addressed the importance of Google Sites as an online teaching tool. We tried to answer the question: What is the influence of Google Sites as an online teaching tool in meaningful learning in the area of Science, Technology and Environment, in fourth grade students of the secondary level at No. 3056 "Gran Bretaña" Public School - Lima, 2017? In response to this question, we formulated the hypothesis that Google Sites as an online teaching tool significantly influences meaningful learning. The work was developed with a quantitative approach, an explanatory scope and a quasi-experimental design. We used a pre-test / post-test model, with two groups: an experimental and a control group. It was executed with a non-probabilistic sample of 46 students ( 22 from the control group and 24 from the experimental group). The instrument we used was the 2017 Regional Diagnostic Test for the Science area applied by the Ministry of Education of Peru to evaluate fourth grade students of secondary education. The results of the contrast allowed us to verify the stated hypothesis, with a level of significance of $p=, 000<, 001$.

Keywords: Google Sites, technological tool, portfolio, digital folder, blog, web, science, technology.

\section{INTRODUCCIÓN}

Resulta evidente que, en pleno siglo XXI, las Tecnologías de la Información y Comunicación (TIC) impactan en diferentes aspectos de la vida y la sociedad, en especial en el campo educativo, al que la tecnología proporciona distintos recursos y herramientas útiles para mejorar los aprendizajes. Por ende, es innegable que, para participar en la sociedad tecnológica actual, el individuo requiere acceder a las TIC y las plataformas virtuales e iniciar así el proceso de rompimiento de las brechas digitales (Hernández, 2017). Pese al avance dinámico del desarrollo tecnológico en el mundo, muchos individuos todavía no se adaptan a los cambios que la realidad les presenta. Resulta indispensable que el sistema educativo integre las TIC en la escuela, use las plataformas virtuales $y$, desde ese espacio, se acorten las brechas digitales. Esto implica el necesario desarrollo de competencias tecnológicas en los docentes, sobre quienes pesa la responsabilidad de ayudar a los estudiantes a adaptarse al enfoque tecnológico que define a la sociedad del nuevo milenio.

El reto de la educación actual exige dejar de lado los modelos tradicionales, ya que en estos tiempos los docentes no pueden decir a los estudiantes qué y cómo aprender, sino que se necesita nuevas formas de aprender en las que los estudiantes interactúen en un clima de confianza y respeto mutuo hacia sus pares y hacia el docente. En España, Campos (2014) comprobó que los padres de familia y docentes de educación primaria percibían como negativa a la metodología de enseñanza tradicional y esto se debería a desacuerdos entre la presión académica y la falta de comunicación entre la escuela y la familia, como también a la falta de adaptación a los ritmos de aprendizaje y a las necesidades emocionales de los estudiantes. Los docentes y padres de familia apuestan por una atención más individualizada y el uso de métodos activos para superar las dificultades actuales. En México, Azamar-Alonso (2015, p. 139) analizó los modelos educativos tradicionales y concluyó que están temporalmente desfasados $y$, frente a los nuevos paradigmas, tienen una utilidad nula; por consiguiente, son incapaces de atender las demandas de la sociedad actual que se torna cada vez más exigente.

En la educación interactiva, a la que se refiere esta investigación, los estudiantes asumen el control de su aprendizaje, autorregulan el proceso y con- 
siguen logros más duraderos. Por esa razón, el paso de una educación tradicional a una sociedad fundamentada en la adquisición de conocimiento implica que los docentes, además de introducir cambios necesarios en sus prácticas metodológicas, cambien de mentalidad y vuelquen su mirada hacia entornos de aprendizaje distintos a los conocidos y exploren las posibilidades educativas de estos (Hernández, 2017, p. 333). La transición requiere de un cambio de roles en los actores del proceso educativo, los docentes ya no pueden continuar administrando o impartiendo conocimientos (CEPLAN, 2014, p. 38). Les corresponde procurar que los estudiantes autogestionen su proceso de aprendizaje y sean capaces de buscar, seleccionar, procesar y utilizar la información de manera independiente, de manera que enfrenten los cambios que experimenta el mundo actual. Necesitan un mayor dominio de las herramientas digitales y usarlas para autosatisfacer sus necesidades de aprendizaje. El docente, media entre los discentes y tales herramientas apostando por el uso responsable y el máximo aprovechamiento de sus beneficios. En este panorama, el aprendizaje se distancia cada vez más de la limitante pizarra tradicional y de los pupitres estáticos y navega en la telarańa de la red, donde la información está disponible para quienes la requieran y sepan usarla y se actualiza y cambia cada segundo.

Estas consideraciones gestaron el interés de los investigadores por recurrir a una herramienta didáctica online que favoreciera el aprendizaje significativo en el área de Ciencia, Tecnología y Ambiente (CTA). Por ello se formuló la pregunta: ¿Cuál es la influencia del Google Sites como herramienta didáctica online en el aprendizaje significativo en el área de Ciencia, Tecnología y Ambiente en estudiantes del cuarto grado del nivel secundaria de la Institución Educativa Publica No 3056 "Gran Bretaña" - Lima, 2017?. Y se desarrolló teniendo como objetivo general determinar la influencia del Google Sites como herramienta didáctica online en el aprendizaje significativo en CTA.

\section{Las TIC en educación}

El ejercicio de la docencia reclama una actuali- zación y promoción de prácticas de enseñanza novedosas, sobre todo la apropiación de nuevas e innovadoras concepciones y tecnologías orientadas a la eficacia y eficiencia del servicio educativo. El uso pedagógico de las TIC impacta de forma positiva en el aprendizaje. Los estudiantes, como nativos digitales, mantienen una estrecha relación con dichas tecnologías. Con ellas amplían su vida social; las usan como herramientas indispensables en los nuevos escenarios de aprendizaje. Las nuevas tecnologías brindan nuevas posibilidades para aprender a aprender y conducir el propio aprendizaje; pero su implantación en un sistema educativo depende de buenas decisiones político-educativas, que son responsabilidad de los gobiernos de turno. Estas decisiones implican una valoración reflexiva de las políticas, estrategias y herramientas a utilizarse en dicho proceso, así como de las prácticas escolares que se sustenten en el uso de las TIC (Colás, De Pablos \& Ballesta, 2018). El proceso tiene un enfoque constructivista: el docente (facilitador) prioriza la participación activa del estudiante en su aprendizaje, lo inserta en la sociedad del conocimiento, que no existe sin la tecnología. La gestión del conocimiento obliga al sujeto a valerse de la tecnología disponible.

Un óptimo sistema educativo debe ser relevante, pertinente y darse en un marco de equidad, eficiencia y eficacia (UNESCO, 2013). Es relevante si desarrolla las competencias necesarias para que el individuo se involucre y participe en actividades humanas afrontando cualquier desafío y desarrollando su proyecto de vida. Es pertinente si permite la apropiación de contenidos provenientes de distintas culturas locales e internacionales, y si esta se desarrolla en forma autónoma y con identidad propia; lo que implica transitar de una pedagogía de la homogeneidad a otra de la diversidad. La educación de calidad se da en un contexto de equidad cuando ofrece al sujeto la oportunidad de ejercer sus derechos a la educación y disfrutar de las mismas oportunidades educativas en igualdad de condiciones. La educación es eficaz si permite el acceso de toda la población a un servicio de calidad y eficiente cuando permite el respeto al derecho del ciudadano a dicho servicio y le reconoce y retribuye el esfuerzo realizado. Lograr la calidad educativa involucra "Mejorar todos los aspectos cualitativos de la educación, 
garantizando los parámetros más elevados, para conseguir resultados de aprendizaje reconocidos y mensurables, especialmente en lectura, escritura, aritmética y competencias prácticas esenciales" (UNESCO, 2014, p. 94).

Las TIC aportan a una educación relevante si: (i) permiten que el sujeto aprenda a conocer, aprenda a ser, aprenda a hacer y aprenda a vivir en comunidad; (ii) ofrecen múltiples alternativas o soportes para el desarrollo de propuestas pedagógicas y la diversificación de la enseñanza y aprendizaje; (iii) el acceso a ellas es equitativo, con disponibilidad de recursos de calidad que permitan alcanzar resultados de aprendizaje óptimos (UNESCO, 2013). Es deber de los docentes prepararse para enseñar y gestionar el aprendizaje de los estudiantes utilizando recursos didácticos pertinentes y relevantes (Ministerio de Educación del Perú, 2012). Esta preparación incluye la búsqueda y selección de herramientas didácticas que faciliten el proceso de aprendizaje-enseñanza. Las TIC, como herramientas didácticas, apoyan la labor docente; motivan al estudiante y hacen más entretenido el aprendizaje, gracias a la dinamización de Internet y la tecnología y la cobertura mundial que tienen estas, en especial en favor de la educación, donde abren espacios para el debate e interacción entre los sectores interesados. Pero es necesario que los avances científicos y tecnológicos marchen a la par con las necesidades humanas (Palacio \& Cabrera, 2017).

La presencia de las TIC en las aulas constituye un tránsito significativo del texto impreso al soporte digital. Esto disminuye de forma considerable el consumo de bosques y la conservación de la salud del planeta. El proceso requiere de la capacidad analítica de los estudiantes, quienes deben: (i) evaluar la necesidad y pertinencia los dispositivos para elegir aquellos que resulten más convenientes a sus necesidades de aprendizaje, (ii) aprender a usarlos en forma responsable y, sobre todo, (iii) apoderarse de la mejor información que estos les pueden proporcionar para utilizarla en la comprensión de nueva información o solucionar situaciones problemáticas relacionadas con las actividades que realiza. Por su parte, los docentes son responsables de formar personas que: autorregulan su comportamiento, muestran una actitud crítica, analítica y reflexiva, aprovechan las herramientas en beneficio de su aprendizaje y dejan de usarlas en actividades inocuas. En ese sentido, el trabajo con Google Sites brinda la oportunidad de acercar a los estudiantes a las plataformas virtuales para desarrollar sus destrezas tecnológicas de la mano con el aprendizaje de alguna materia.

\section{Google Sites como herramienta didáctica online}

Está claro entonces que la tecnología digital interviene en todas las actividades humanas; incide en los cambios educativos, familiares y laborales (UNESCO, 2013). No se puede concebir la vida humana desvinculada de la tecnología, pues esta no solo trae comodidad a la vida del hombre, sino que facilita muchas de sus actividades y modifica sus destrezas cognitivas. Por ende, la incorporación de la tecnología a la escuela implica digitalizar las aulas incorporando dispositivos (pc, Tablet, celular) para el acceso a información variada y pertinente en el aprendizaje. Estos valiosos recursos complementan la labor del docente y sirven para que el estudiante se adapte al entorno cada vez más cambiante, siendo capaz de adquirir y construir conocimiento (Hernández, 2017).

En ese contexto surge Google Sites (GS), como aplicación online gratuita creada en el año 2008 por la empresa estadounidense Google. Esta plataforma facilita la recepción de actividades, la producción de textos, la difusión de tareas y productos de aprendizaje, así como la incorporación de distintos ritmos de trabajo y la individualización en la revisión de tareas y comentarios a estas (Ambròs \& Ramos, 2017). Como herramienta didáctica, GS permite que el docente planifique las actividades didácticas, convirtiéndolas en experiencias motivadoras y entretenidas que favorecen la construcción del aprendizaje.
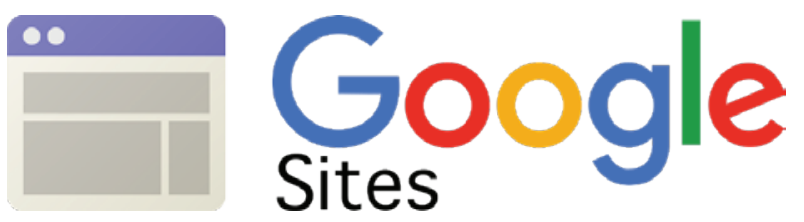

Figura 1.

Logo de Google Sites (GS).

Fuente: https://www.cookman.edu/cit/webservices/googlesites.html 
Las características, funciones y utilidad de Google Sites

La plataforma Google Sites se caracteriza porque en ella la información y comunicación fluyen sin parar. Permite la creación de sitios web personalizados y páginas web prescindiendo de HTML u otros lenguajes de programación complejos (Wojcicki, Izumi, Chang, Parisi \& Silerman, 2016). Su uso no requiere descarga ni instalación de algún software o programa, tampoco exige conocimiento o aplicación de complejos lenguajes de programación. Su diseño y construcción es intuitivo, amigable, ameno y fácil de manejar. Se accede a esta plataforma desde cualquier ordenador o equipo tecnológico y solo se necesita una conexión a Internet. Una vez que el propietario diseña el sitio web con GS, él y los usuarios reunirán en un solo lugar información variada de distintas áreas del conocimiento. Como vídeos, imágenes, mapas, calendarios, presentaciones, hojas de cálculo, archivos adjuntos y de texto, registrar enlaces, entre otros. Algo a tener en cuenta es el espacio limitado del que dispone un usuario de la versión gratuita (hasta $100 \mathrm{MB}$ ), a diferencia del uso por suscripción de la plataforma, que garantiza un espacio más amplio.

Son funciones de Google Sites (Wojcicki et al., 2016):

a. Crear y actualizar en forma personalizada el sitio.

b. Crear subpáginas para mantener el sitio organizado en torno a ideas concretas.

c. Elegir el tipo de página más conveniente: página web (la más simple), anuncios (muestran las entradas publicadas) o archivos.

d. Determinar la ubicación central para el sitio web y los archivos que se alojarán en este.

e. Decidir si el mantenimiento del sitio es público o privado.

f. Buscar en el contenido del sitio a través del Google Search o buscador.

Google Sites es una herramienta útil en la labor docente. Facilita la creación de páginas web con contenido multimedia, a partir de la selección de plantillas predeterminadas. Permite recopilar la información en un solo lugar (funciona como repositorio digital), almacenar material impor- tante, de interés para los usuarios y en formatos distintos. El administrador controla quién puede ver y editar la información; si esta será de dominio público (ubicado y accedido por cualquier usuario de Internet) o privado (solo accesible por aquellas personas a las que se les permite explícitamente hacerlo). Inclusive, se puede invitar a otros usuarios y permitirles editar los contenidos o sólo verlos. Gracias a esta posibilidad de interacción, GS tiene un poderoso impacto en el trabajo colaborativo, pues los miembros del grupo pueden ver el trabajo de los demás integrantes y aporta a la mejora del producto. Además, GS admite la retroalimentación.

Las características, funciones y utilidad de Google Sites antes reseñados se tuvieron en cuenta al emplear dicha plataforma para desarrollar el aprendizaje significativo en CTA.

\section{Aplicación de Google Sites en las aulas}

En la sociedad del siglo XXI, caracterizada por una serie de retos, GS permite la construcción compartida de conocimiento (Ambròs \& Ramos, 2017). El aprendizaje y el conocimiento no pueden estar desligados de la tecnología. Se trata de saber buscar información, procesarla, seleccionar la más importante y aplicarla en la solución de problemas académicos, sociales, laborales o familiares. Por tanto, las personas son competentes si utilizan herramientas tecnológicas para acceder a esa información, apoderársela y aplicarla en la superación de las dificultades que se les presenten.

Si bien hay otras plataformas que ofrecen servicios parecidos y con aplicaciones educativas que conducen a resultados semejantes (Entorno de Aprendizaje Virtual - Virtual learning environment (VLE), Sistema de Gestión de Aprendizajes - Learning Management System (LMS), Sistema de Gestión de Cursos - Course Management System (CMS), Entorno de Gestión de Aprendizajes - Managed Learning Environment (MLE), Sistema Integrado de Aprendizajes - Integrated learning system (ILS), Plataforma de Aprendizajes - Learning Plataform (LP), Campus Virtual (CV), Aula Virtual (AV)...) en esta investigación se optó por Google Sites debido a la familiaridad que los estudiantes tenían con el navegador Goo- 
gle. Es importante que aprendan a ver a Google no como un simple navegador, sino como una gran plataforma que les brinda, además, otras herramientas útiles para su aprendizaje.

El uso adecuado de la plataforma GS en educación brinda la oportunidad de crear un sitio web para realizar un trabajo colaborativo efectivo, dentro y fuera de las aulas, (Gonzáles, 2014). Permite al usuario:

- Creación de libros o apuntes digitales. El docente, como propietario y según las unidades didácticas, asigna a las páginas actividades que los estudiantes pueden desarrollar en un determinado periodo lectivo.

- Compilación de trabajos producidos por los discentes. En función de proyectos o temas específicos. La plataforma funciona como portafolio digital de los productos de aprendizaje.

- Configuración de una biblioteca o repositorio digital. Docente y estudiantes proponen un listado de recursos (audios, videos, imágenes, documentos de variados formatos, entre otros) disponibles mediante links o enlaces a páginas web.

- Creación de listas de tareas o proyecto pedagógicos a desarrollar. El docente indica las pautas a seguir, las fases a desarrollarse durante la realización del proyecto y publica la rúbrica que se empleará en la evaluación.

- Realización de blogging. El docente y los estudiantes difunden información de interés, exponiendo sus puntos de vista con respecto a esta.

El aprendizaje significativo en el área de Ciencia, Tecnología y Ambiente (CTA)

Enfoques del área de CTA. La alfabetización, la cultura científica y tecnológica, asi como la educación en Ciencia, Tecnología y Sociedad (CTS) se han convertido en demandas latentes de todos los pueblos del mundo (Ministerio de Educación de Perú, 2015). La enseñanza de las ciencias promueve y promociona los conocimientos cientificos y tecnologicos como parte de la educación básica para todos, con una perspectiva global y vinculados a los problemas de desarrollo social. Se tiene una orientación humanista impregnada de valores que ayudan en la resolución y superación de los problemas de salud, energéticos y ambientales latentes.

El Ministerio de Educación de Perú (2013) señala que el área de CTA tiene dos enfoques: El de la indagación científica y el de la alfabetización científica y tecnológica, que se detallan a continuación.

El enfoque de indagación científica. Comprende el conjunto de procesos que permiten habilidades científicas. A partir de su relación con el mundo natural, el estudiante construye conocimientos y comprende el mundo circundante. El término indagación no solo se utiliza dentro del contexto educativo y para la enseńanza de las ciencias, se aplica también en la vida cotidiana, porque todos de alguna forma buscan explicaciones o respuestas para preguntas relacionadas con lo que viven a diario. La indagación permite a los estudiantes lograr aprendizajes cientificos (Ministerio de Educación de Perú, 2015), les fija la idea de hacer ciencia; es decir, no basta "saber algo", sino que es necesario conocerlo científicamente. Con este nivel de comprensión, nadie puede ser engañado por ciertos acontecimientos de la realidad o pronunciamientos públicos.

Pero hay que distinguir entre la indagación como objetivo de aprendizaje y la indagación como método didáctico. La primera es un componente del conocimiento acerca de la naturaleza propia de la ciencia; la segunda permite obtener conocimiento en la clase de ciencias (Caamaño, Cañal \& De Pro, 2012). El docente que enseña ciencias define con claridad el tipo de indagación que los estudiantes realizarán en una actividad, conociendo que los seres humanos son curiosos por naturaleza. Desde pequeños se formulan preguntas sobre distintos fenómenos naturales. El buen docente aprovecha esta característica y diseña actividades indagatorias que requieren de un trabajo científico, colaborativo, con demanda de habilidades sociales, lingüísticas y de comunicación. (Tabla 1)

El enfoque de la indagación científica es formativo, privilegia el desarrollo de las competencias, reconoce al docente como guía en los procesos de indagación y promueve el uso adecuado de recursos y materiales didácticos, estrategias e instru- 
mentos de evaluación. Además, se da una mirada humana a la naturaleza, la ciencia y el trabajo científico (Ministerio de Educación de Perú, 2013).

Tabla 1

Propuesta metodológica para el desarrollo de la indagación

- Generar un escenario práctico para la enseñanza y el aprendizaje, donde el estudiante plantee preguntas y obtenga respuestas desde el análisis de información.

- Otorgar al estudiante un rol activo para que, gracias a su protagonismo, actitud y motivación por el trabajo en equipo, pueda incluso decidir el tema a trabajar.

- Enfatizar que el docente solo guía y facilita la indagación.

- Organizar la indagación y guiar a los estudiantes por cinco etapas: (i) motivar-enganchar-involucrar, (ii) explorar-investigar, (iii) explicar, (iv) extender-elaborar y (v) evaluar.

Fuente: Ministerio de Educación de Perú (2015a)

Enfoque de la alfabetización científica. Al enseñar ciencia se generan situaciones de aprendizaje que relacionan los saberes previos y los fenómenos naturales de manera que el sujeto se interrogue y elabore explicaciones según modelos formales y generalizadores propios de las ciencias naturales (Ministerio de Educación de Perú, 2013). En virtud de este enfoque, los estudiantes adquieren elementos para leer y comprender el entorno. La alfabetización científica y tecnológica aspira a que los estudiantes se desenvuelvan en el mundo, conozcan la importancia de aquellas en su vida personal y social y, como ciudadanos, reflexionen y tomen decisiones informadas. En virtud de la alfabetización científica, los estudiantes comprenden ideas clave para explicar científicamente lo que observan. La alfabetización conlleva al fomento de actitudes favorables y positivas hacia la ciencia (Garmendia \& Guisasola, 2015).

\section{Competencias del área de Ciencia, Tecnología y Ambiente}

Las competencias son facultades de la persona para saber actuar de manera pertinente en un determinado contexto usando de manera flexible y creativa todas sus capacidades y recursos. Estas capacidades son conocimientos, habilidades, valores y actitudes de los que dispone el sujeto para alcanzar un objetivo o solucionar un problema del entorno (Ministerio de Educación de Perú, 2015a y 2015c). Una persona competente ha logrado aprendizajes complejos de carácter longitudinal, alcanzan niveles cada vez más altos de desempeño y, en razón de esto, actúan en un contexto particular. Según objetivos o la solución de un problema, movilizan los saberes adquiridos en diferentes situaciones, dentro y fuera de la escuela. En el marco de Pisa 2015 (Ministerio de Educación de Perú, 2015b) se explica que las "competencias se articulan mediante una serie de términos que definen la demanda cognitiva a través del uso de capacidades como reconocer, interpretar, analizar y evaluar" (p. 18). Pero las referidas competencias no señalan ningún orden jerárquico, sino que la respuesta a las demandas cognitivas depende de los conocimientos requeridos.

Las competencias científicas permiten hacer ciencia, aplicar la ciencia y la tecnología para explicar el mundo; propician la convivencia pacífica, en armonía con el ambiente físico. Su desarrollo se relaciona con la indagación, el manejo de conceptos, teorías, principios, leyes y modelos de las ciencias naturales que permiten entender y explicar el mundo (Ministerio de Educación de Perú, 2015b); también con el impulso de formas de vida sanas, la innovación del diseño y producción de prototipos tecnológicos para solucionar problemas, reflexionar, emitir juicios de valor y convivir en forma pacífica y respetuosa. La figura 2 muestra las cuatro competencias señaladas en Rutas de Aprendizaje de CTA (Ministerio de Educación, de Perú, 2015c, p. 10).

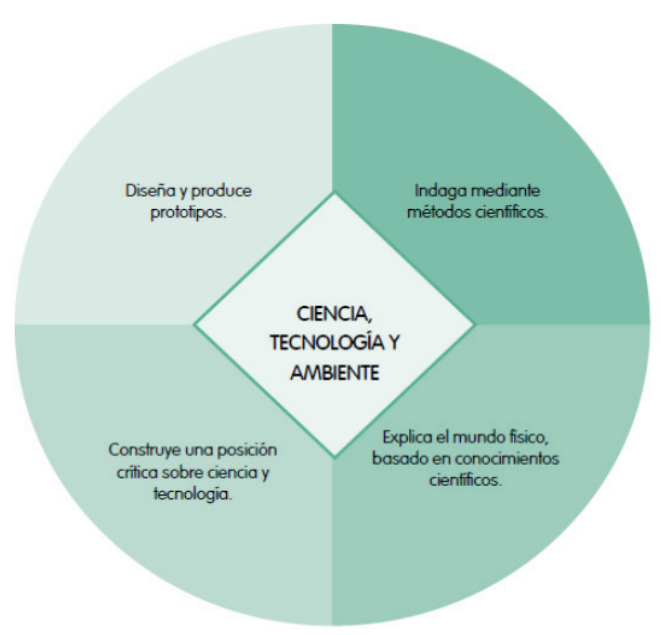

Figura 2

Competencias de Ciencia, Tecnología y Ambiente. Fuente: Rutas del Aprendizaje. Área Ciencia, Tecnologia y Ambiente (2015c, p. 10). 
Google Sites como herramienta didáctica online en el aprendizaje significativo del área de ciencia, tecnología y ambiente en estudiantes de cuarto grado de educación secundaria

El Ministerio de Educación de Perú (2017) define a la competencia como "la facultad que tiene una persona de combinar un conjunto de capacidades a fin de lograr un propósito específico en una situación determinada, actuando de manera pertinente y con sentido ético" (p. 29). Es decir, la persona competente usa de forma articulada, deliberada y consciente las capacidades que posee para enfrentarse situaciones nuevas y resolver los retos o situaciones problemáticas de su realidad personal, familiar o social.

En la Tabla 2 se observa que, en Rutas de Aprendizaje (Ministerio de Educación de Perú, 2015c, p. 10), se consideraban cuatro competencias, a diferencia de PISA, que solo trabajó con tres. Sin embargo, en el Currículo Nacional de la Educación Básica (Ministerio de Educación de Perú, 2017, pp. 33-34) se fijan solo tres competencias. De estas, la primera y la segunda son muy parecidas a sus homólogas en PISA, pero la tercera difiere. PISA considera la competencia "Interpretar datos y pruebas científicamente" y el Currículo Nacional establece la competencia "Indaga mediante métodos científicos para construir conocimientos" (Ministerio de Educación de Perú (2015a, p. 17; 2015b, p 32).

La competencia científica requiere que las personas con conocimientos de ciencia y tecnología juzguen la importancia de las investigaciones previas y conozcan el valor de las nuevas investigaciones científicas. Si bien la tecnología se basa en la ciencia, ambas tienen claras diferencias en cuanto a objetivos, propósitos y productos. La ciencia busca respuestas a preguntas específicas, mientras que la tecnología persigue soluciones para los problemas. Sin embargo, hay entre ellas vinculaciones estrechas.

La presente investigación asumió las competencias de Rutas de Aprendizaje para CTA, versión 2015 (Ministerio de Educación de Perú, 2015c), indicadas en la tabla 1 , por ser estas las que estuvieron vigentes durante el año escolar en el cual se desarrolló el trabajo experimental. Estas competencias son:

Indaga, mediante métodos científicos, situaciones que pueden ser investigadas por la ciencia. El desarrollo de esta competencia está asociado a cinco capacidades:

\section{Tabla 2}

Las competencias científicas según PISA 2015 y Rutas de Aprendizaje de CTA y el Currículo Nacional de Educación Básica

\begin{tabular}{|c|c|c|}
\hline PISA 2015 & $\begin{array}{c}\text { Rutas de Aprendi- } \\
\text { zaje de CTA }\end{array}$ & $\begin{array}{l}\text { En el Currículo } \\
\text { Nacional de la Edu- } \\
\text { cación Básica }\end{array}$ \\
\hline $\begin{array}{l}\text { Explicar fenóme- } \\
\text { nos científica- } \\
\text { mente }\end{array}$ & $\begin{array}{l}\text { Explica el mundo } \\
\text { físico, basado en } \\
\text { conocimientos } \\
\text { científicos. }\end{array}$ & $\begin{array}{r}\text { Explica el mundo } \\
\text { físico basándose en } \\
\text { conocimientos so- } \\
\text { bre los seres vivos; } \\
\text { materia y energía; } \\
\text { biodiversidad, } \\
\text { Tierra y universo }\end{array}$ \\
\hline \multirow[t]{2}{*}{$\begin{array}{l}\text { Evaluar y diseñar } \\
\text { la investigación } \\
\text { científica }\end{array}$} & $\begin{array}{l}\text { Diseña y produce } \\
\text { prototipos tec- } \\
\text { nológicos para re- } \\
\text { solver problemas } \\
\text { de su entorno. }\end{array}$ & $\begin{array}{r}\text { Diseña y construye } \\
\text { soluciones tecnoló- } \\
\text { gicas para resolver } \\
\text { problemas de su } \\
\text { entorno }\end{array}$ \\
\hline & $\begin{array}{l}\text { Construye una } \\
\text { posición crítica } \\
\text { sobre la ciencia y } \\
\text { la tecnología en } \\
\text { sociedad. }\end{array}$ & \\
\hline $\begin{array}{l}\text { Interpretar datos } \\
\text { y pruebas científi- } \\
\text { camente. }\end{array}$ & $\begin{array}{l}\text { Indaga, mediante } \\
\text { métodos científi- } \\
\text { cos, situaciones } \\
\text { que pueden ser } \\
\text { investigadas por } \\
\text { la ciencia }\end{array}$ & $\begin{array}{r}\text { Indaga mediante } \\
\text { métodos científicos } \\
\text { para construir } \\
\text { conocimientos }\end{array}$ \\
\hline
\end{tabular}

Fuente: Ministerio de Educación de Perú (2015a; 2015b, pp. 32-33; 2015c, p. 10 y 2017, pp. 33-34).)

(i) problematiza situaciones, (ii) diseña estrategias para hacer una indagación, (iii) genera y registra datos e información, (iv) analiza datos o información y (v) evalúa y comunica (Ministerio de Educación de Perú, 2015c, p. 12 y 2017, p. 120).

La indagación científica es "un proceso reflexivo de exploración, planificación, comunicación, construcción y re-construcción" del conocimiento (González-Weil et al. 2012, p. 101). Al indagar, los estudiantes producen nuevos conocimientos que puede enriquecer con la experimentación y respaldarlos con experiencias, conocimientos previos y evidencias obtenidas. Usan métodos científicos e indagan en situaciones problemáticas del entorno; generan información, la registran, analizan, evalúan y comunican el resultado del análisis reflexivo. La indagación científica, más que una simple recepción y trasmisión de conocimientos, 
es una excelente alternativa para la apropiación y uso de métodos en la construcción conocimiento (Flórez-Nisperuza \& De la Ossa, 2018, p. 63).

En PISA 2015, la competencia científica "explicar fenómenos científicamente" (Ministerio de Educación, 2015b, p. 34) exige que, en determinadas situaciones, se utilicen conocimientos apropiados para generar hipótesis explicativas donde no hay conocimientos o datos. En el proceso, no solo se recuerdan y aplican los conocimientos, sino que se emplean modelos para formular hipótesis, realizar predicciones y explicar las implicancias del conocimiento científico. La enseñanza en ciencia garantiza que docentes y estudiantes usen estrategias para apropiarse de conocimientos científicos y tecnológicos imprescindibles para interpretar cuanto acontecen en el mundo natural (Caamaño et al., 2012). Así pues, el reto para ambos consiste en modernizar los conocimientos existentes.

Explica el mundo físico, basado en conocimientos científicos. Esta competencia combina dos capacidades: “(i) Comprende y usa conocimientos sobre los seres vivos, materia y energía, biodiversidad, Tierra y universo y (ii) Evalúa las implicancias del saber y del quehacer científico y tecnológico" (Ministerio de Educación de Perú, 2015c, p. 27 y 2017, p. 125). En la primera, el estudiante establece relaciones entre conceptos; construye representaciones del mundo mediante explicaciones, ejemplificaciones, aplicaciones, justificaciones, comparaciones, contextualizaciones y generalizaciones al aplicar los conceptos a otras situaciones. En la segunda, asume posturas críticas o toma decisiones según sus saberes locales, evidencias empíricas y científicas para la conservación del ambiente (local y global) y mejorar su calidad de vida.

Diseña y produce prototipos tecnológicos para resolver problemas de su entorno. $\mathrm{El} \mathrm{CN}$ de $\mathrm{EB}$ (Ministerio de Educación de Perú, 2015c, pp. 44-45 y 2017, p. 128) señala que, para el logro de la competencia diseńa y produce prototipos tecnológicos, los estudiantes combinan e integran cuatro capacidades: "(i) determina una alternativa de solución tecnológica, (ii) diseña alternativas de solución tecnológica, (iii) implementa la alternativa de solución tecnológica y (iv) evalúa y comunica el funcionamiento y los impactos de su alternativa de solución tecnológica” (p. 128).

Gracias a la tecnología, el hombre ha creado muchas cosas artificiales, pero su accionar tecnológico pone en riesgo al medio ambiente, inclusive la existencia y supervivencia humana. Ante esto, corresponde considerar a la tecnología como parte del sistema ecológico, al que necesita conocer, comprender y entender. Solo así se maximizarán los beneficios, se minimizarán los riesgos y podría hablarse de una cultura tecnológica.

La tecnología está en todos lados, en cada actividad humana. Si bien en la escuela los estudiantes aprenden acerca del funcionamiento, comportamiento y composición del mundo natural mediante el aporte de distintas disciplinas científicas, necesitan conocer los fundamentos científicos, los principios que rigen el funcionamiento y el comportamiento de los objetos que integran el mundo artificial. La tecnología, utilizada en la práctica educativa, integra la teoría con la práctica. La enseñanza de las ciencias pretende que los egresados lleven consigo conocimientos básicos, ideas, conceptos y procedimientos para conocer la ciencia y aplicarla en la solución de problemas relacionados con la naturaleza circundante (UNESCO, 2016).

La educación enfrenta el reto de solucionar problemas medioambientales mundiales. Esta preocupación global apunta al desarrollo de una actitud preventiva respecto al deterioro del planeta, así como al control de lo que lo genera y los efectos que el cambio climático produce en la humanidad (UNESCO, 2014). El camino para lograrlo está en la mejora de los conocimientos, el fomento de valores, el afianzamiento de convicciones sobre la necesidad de prevenir y evitar la destrucción, la modificación de comportamientos nocivos para la salud del planeta. Hablar de calidad de vida es pensar en una educación ambiental que despierta conciencias y avidez por la generación de conocimientos para resolver los problemas que afectan al ambiente local y globa, la cual está ligada a la innovación tecnológica; es una alternativa para enfrentar los problemas medioambientales. Por lo que hay necesidad de mejorar las políticas de innovación tecnológica, pues, además de sus aplicaciones al campo de la educación, está vinculada 
Google Sites como herramienta didáctica online en el aprendizaje significativo del área de ciencia, tecnología y ambiente en estudiantes de cuarto grado de educación secundaria

al crecimiento económico de una nación. En investigaciones bien documentadas se ha comprobado que las variables tecnológicas impactan en el crecimiento de la economía de las naciones (Velazquez \& Salgado, 2016).

Construye una posición crítica sobre la ciencia y la tecnología en sociedad. Hay una serie de capacidades que permitirán alcanzar el desarrollo de esta competencia. Estas son: "(i) evalúa las implicancias del saber y del quehacer científico y tecnológico y (ii) toma una posición crítica frente a situaciones socio científicas. Los estudiantes establecen relaciones entre ciencia, tecnología y sociedad" (Ministerio de Educación de Perú, 2015c, pp. 58-59). Estas relaciones se manifiestan en el ámbito social y tienen implicancias paradigmáticas originadas en el saber científico. La adopción de una postura crítica supone plantear alternativas de solución efectivas y sostenibles que mejoren la calidad de vida del individuo. Como estrategia recomendada para el logro de esta competencia se propone, evaluar los conocimientos previos para conocer la posición inicial de los estudiantes frente a un determinado problema y, a partir de estos, plantearles dilemas sociocientíficos, en los que, desde el análisis y reflexión, se llegue a conclusiones individuales, de grupos de trabajo o a nivel de toda la clase.

\section{El programa experimental Google Sites}

Conforme a la tabla 3, el trabajo utilizando Google Sites como herramienta didáctica online en el aprendizaje significativo en el área de CTA estuvo integrado por 12 sesiones de aprendizaje. En cada sesión se usó la plataforma GS, de manera que el aprendizaje previsto fuera un producto de la interacción entre el estudiante y la herramienta tecnológica elegida. La ejecución de las sesiones de aprendizaje se basó en un enfoque formativo y el desarrollo de las competencias científicas, como parte de la formación integral de los estudiantes de educación secundaria.
Tabla 3

Distribución de la muestra

\begin{tabular}{|c|c|c|}
\hline & Título de la sesión & Componente de GS \\
\hline 1 & Extinciones masivas & Sitio Web/Blog \\
\hline 2 & Evolución humana & Sitio Web/Wiki \\
\hline 3 & Química de los seres vivos & Sitio Web/Archivador digital \\
\hline 4 & $\begin{array}{l}\text { Los glúcidos, moléculas } \\
\text { energéticas }\end{array}$ & Sitio Web/Archivador digital \\
\hline 5 & $\begin{array}{l}\text { Los lípidos, moléculas ener- } \\
\text { géticas }\end{array}$ & Sitio Web/Archivador digital \\
\hline 6 & $\begin{array}{l}\text { Vitaminas, moléculas regula- } \\
\text { doras }\end{array}$ & Sitio Web/Portafolio digital \\
\hline 7 & Agua, molécula de vida & Sitio Web/Blog \\
\hline 8 & Los minerales en nuestra vida & Sitio Web/Wiki \\
\hline 9 & $\begin{array}{l}\text { Desentrañando los misterios de } \\
\text { le célula }\end{array}$ & Sitio Web/Archivador digital \\
\hline 10 & Mundo microscópico & Sitio Web/Portafolio digital \\
\hline 11 & $\begin{array}{l}\text { Ciclo celular, garantizando la } \\
\text { supervivencia }\end{array}$ & Sitio Web/Portafolio digital \\
\hline 12 & $\begin{array}{l}\text { Los procesos para obtener } \\
\text { nutrientes, la digestión }\end{array}$ & Sitio Web/Portafolio digital \\
\hline
\end{tabular}

Fuente: programa experimental, 2017.

La competencia científica prioriza la explicación de los fenómenos, más allá de la simple identificación y utilización de los conocimientos (Turpo, 2016, p. 24). Es decir, se trata de que, a partir de los conocimientos que adquieren sobre los fenómenos observados, los estudiantes expliquen lo que ocurre a su alrededor, teniendo como base los diferentes conocimientos adquiridos durante la clase.

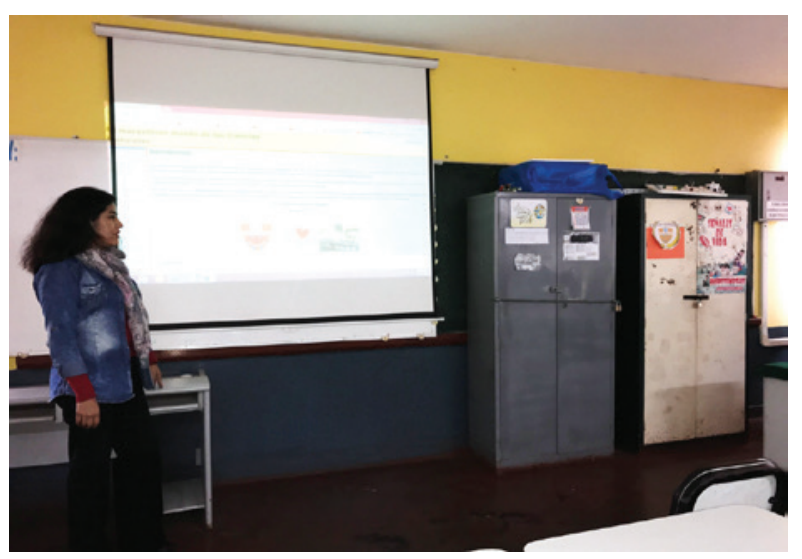

Figura 2

Presentación del programa experimental en el Aula de Innovación Pedagógica (AIP). 


\section{Componentes del programa}

El programa se desarrolló considerando cuatro componentes de la plataforma utilizada para que los estudiantes desarrollen las actividades de aprendizaje propuestas: sitio web, wiki, portfolio digital y archivador digital.

El sitio web (SW). Es el lugar desde donde los estudiantes accedieron a importante y variada información, organizada convenientemente según lo planificado por el docente (Aubry, 2012). Este sitio fue el medio para que el estudiante conociera y resolviera las actividades propuestas según cada propósito de aprendizaje. El SW es el contenedor principal de todo lo planificado. Desde él es posible encontrar los elementos que componen la página principal, los mismos que responden a un diseño y contenido visualmente atractivo para los usuarios. En la creación del SW denominado: El maravilloso mundo de las Ciencias Naturales se utilizó un diseño sencillo y de facil acceso (encabezado, cuadro lateral y cuerpo de la página). El diseño permitió la insercion de textos, imágenes, videos, enlaces, tablas y ofreció la posibilidad de comentar, adjuntar documentos y editarlos. Los usuarios pudieron participar para, con sus aportes, enriquecer el trabajo previo.

La wiki. Wiki es una palabra de origen hawaiano que significa "rápido". La wiki es un espacio de escritura colaborativa (Ramos \& Ramos, 2011). Facilita la creación y modificación de contenidos de manera sencilla, flexible y rápida. El administrador de la wiki fue propietario del espacio, invitó a los estudiantes y les otorgó la posibilidad de editar los materiales publicados. Así se favoreció el trabajo colaborativo y se dio espacio para la retroalimentación por cuenta de todos los participantes. Durante el proceso se desarrollaron las sesiones de aprendizaje que, partiendo del planteamiento de preguntas retadoras, buscaron que los estudiantes respondan y construyan colaborativamente el espacio. Las actividades se vieron enriquecidas por las variadas herramientas de GS, como la inserción de documentos, hipervínculos, imágenes y videos.

El portafolio digital (PD). Fue el espacio para que el estudiante publicara el trabajo realizado en cada actividad propuesta (Cacheiro, Sánchez \& Gon- zález, 2015). El PD conserva evidencias sobre los aprendizajes de los estudiantes. En las sesiones desarrolladas con este componente se pretendió que los estudiantes diseñen y construyan diferentes recursos, almacenados grupalmente en el portafolio. Esto rompió la idea tradicional que se tiene de este, pues se logró la incorporación de diferentes elementos multimedia para que los productos de los estudiantes fueran accesibles, atractivos y estuvieran disponibles para todos los usuarios. El diseño y elaboración de los productos demandó un tiempo y esfuerzo adicional, pero valió la pena pues al final se evidenciaron los resultados.

El archivador digital (AD). También llamado fichero, es un espacio donde se puede almacenar documentos en diferentes formatos, que los estudiantes pueden descargar fácilmente. $\mathrm{El} \mathrm{AD}$ es una herramienta sencilla y segura que facilitó a los estudiantes la ubicación de sus documentos en las páginas creadas para cada sesión de aprendizaje. Los documentos tuvieron nombre propio y la extensión característica que identifica a la aplicación utilizada.

La experiencia pedagógica del docente y la experiencia de aprendizaje de los estudiantes se vieron enriquecidas por el uso de la plataforma GS, que se convirtió en un elemento motivador y de gran utilidad para promover en estos últimos la indagación científica, diseñar y producir prototipos tecnológicos, elaborar una explicación del mundo circundante y dar una mirada crítica a la ciencia y la tecnología en el desarrollo personal, familiar, social, académico y laboral de los estudiantes. Los hallazgos refrendan la hipótesis de investigación y sirven de base para una reflexión acerca del rumbo que debe seguir la práctica pedagógica en la enseñanza de CTA.

\section{Materiales Y Métodos}

\section{Participantes}

El estudio se realizó en la Institución Educativa No 3056 "Gran Bretaña”, ubicada en el distrito de Independencia en Lima Norte. La investigación se ejecutó con una muestra de 88 estudiantes de cuarto grado de Educación Secundaria (46 
Google Sites como herramienta didáctica online en el aprendizaje significativo del área de ciencia, tecnología y ambiente en estudiantes de cuarto grado de educación secundaria

varones y 42 mujeres), distribuidos en cuatro secciones como se muestra en la Tabla 4.

Tabla 4

Distribución poblacional de estudiantes de cuarto grado de educación secundaria de la Institución Educativa No 3056 "Gran Bretaña”

\begin{tabular}{cccc}
\hline Secciones & Varones & Mujeres & Subtotal \\
\hline A & 12 & 10 & 22 \\
B & 13 & 11 & 24 \\
C & 13 & 11 & 24 \\
D & 8 & 10 & 18 \\
\hline Total & 46 & 42 & 88 \\
\hline
\end{tabular}

Fuente: Nomina de matrícula - Sistema de Información de Apoyo a la Gestión de la Institución Educativa SIAGIE (2017).

La muestra no probabilística, de tipo intencional y grupos intactos, estuvo formada por los 46 estudiantes de las secciones A (Grupo de control, con 22 estudiantes) y C (Grupo experimental, con 24 estudiantes). Para elegir los grupos, se tuvo en cuenta la media de las calificaciones en CTA y se eligió a los dos grupos que tenían la media más baja. Se asumió este criterio para tener como referencia común a dos grupos con el rendimiento más bajo y, posteriormente, verificar las probables mejoras en uno de ellos (grupo experimental), como consecuencia del estímulo recibido con la variable independiente.

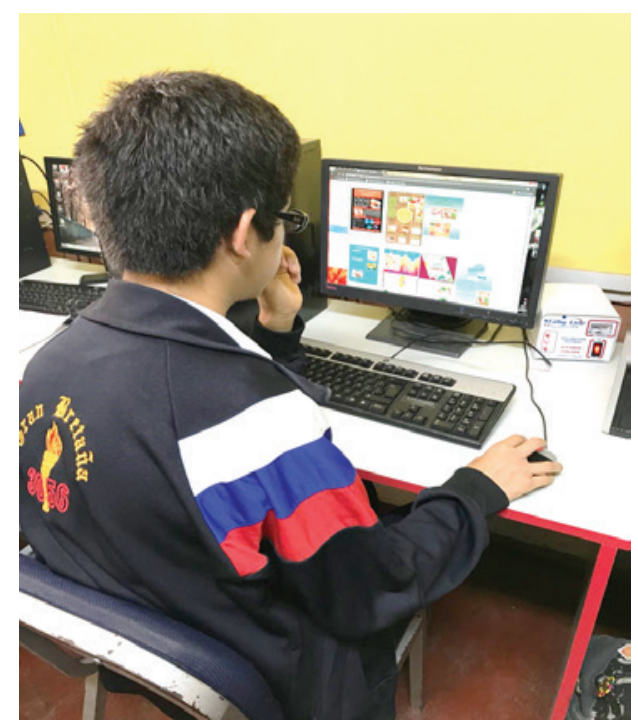

Figura 4

Desarrollo de actividades realizadas por los alumnos del grupo experimental.

\section{Instrumento}

La técnica empleada es la evaluación tipo test, que deriva en valoraciones acerca del aprendizaje de los sujetos evaluados. La finalidad de este tipo de evaluación fue obtener respuestas uniformes que permitieran verificar estadísticamente los objetivos de la investigación (Ministerio de Educación de Perú, 2004).

El instrumento utilizado para evaluar el aprendizaje en el área de CTA fue la Prueba Diagnóstica Regional 2017, elaborada y distribuida por el Ministerio de Educación de Perú para administrarse a estudiantes del cuarto grado de educación secundaria. La prueba evalúa el nivel de logro de los estudiantes en cada una de las competencias de dicha área. A partir de los resultados, los docentes toman decisiones acerca de las situaciones de aprendizaje que deben planificarse en las sesiones de clase, teniendo como base un enfoque formativo y el desarrollo de las competencias del área.

$\mathrm{El}$ instrumento tiene 20 ítems distribuidos en cuatro competencias (Ministerio de Educación de Perú, 2015c, p. 11):

- Indaga, mediante métodos científicos, situaciones que pueden ser investigadas por la ciencia (Ítems 1 al 6).

- Explica el mundo físico, basado en conocimientos científicos (Ítems 7 al 14).

- Diseña y produce prototipos tecnológicos que resuelven problemas de su entorno (Ítems 15 al 18).

- Construye una posición crítica sobre la ciencia y la tecnología en sociedad (Ítems 1 al 19-20).

La prueba diagnóstica se administró en forma individual en un tiempo establecido de 60 minutos. Cada ítem ofrece cuatro alternativas, calificadas con 0 (incorrecto) y 1 (correcto). El puntaje mínimo es 0 y el más alto 20 .

El desarrollo de las sesiones de aprendizaje con ambos grupos se desarrolló según la secuencia temática descrita en la tabla 3 y con intervención de un mismo mediador. Con el grupo de control, el trabajo se desarrolló en la forma convencional, con los materiales y herramientas disponibles en un aula de clase tradicional. Con el grupo experi- 
mental, el desarrollo de las sesiones se dio usando la plataforma GS y los recursos que esta ofrece, desde el Aula de Innovación pedagógica.

\section{Tipo y diseño}

La investigación fue de tipo aplicada y enfoque cuantitativo. Comprendió la recolección numérica de datos que se analizaron mediante estadística descriptiva e inferencial para someter a contraste las hipótesis de investigación (Hernández \& Mendoza, 2018). Es de alcance explicativo, pues tuvo por finalidad explicar la influencia del Google Sites como herramienta didáctica online para el aprendizaje significativo en el área de CTA. Se desarrolló con un diseño cuasiexperimental, modelo preprueba-posprueba y un grupo de control (Hernández \& Mendoza, 2018).

\section{Procedimiento}

La investigación se desarrolló en cuatro fases: planificación, ejecución, análisis de datos y reporte de resultados.

Fase de planificación. Se elaboró el programa experimental, que constó de 12 sesiones incluidas en la tercera unidad didáctica correspondiente al segundo bimestre. La prueba empleada fue elaborada, validada y administrada por el Ministerio de Educación de Perú como parte de la verificación de los aprendizajes de los estudiantes peruanos. En esta etapa se tramitaron las autorizaciones para la ejecución del experimento, recibiendo respuestas favorables.

Fase de ejecución. Completada la planificación del trabajo, se administró el pre test de la prueba a los dos grupos de la muestra (experimental y de control). A continuación, se procedió a desarrollar el programa en 12 sesiones efectivas de trabajo y según los componentes considerados en la variable Google Sites.

En principio, para el mediador, fue importante el aprendizaje mismo de Google Sites, pues dicho conocimiento permitió identificar las opciones de trabajo que ofrece la plataforma para el diseño y construcción de diversas actividades de aprendizaje. Durante el desarrollo de las sesiones, a los estudiantes, como nativos digitales, les resultó bastante natural la interacción con las tecnologías, sobre todo porque les permitió descubrir una nueva forma de aprender en forma colectiva la ciencia, ya que esta herramienta didáctica favorece en gran medida este tipo de trabajo.

Con GS se creó una página web que contiene los recursos propuestos por el mediador para el aprendizaje de los temas. Simultáneamente, los receptores de las actividades de aprendizaje y los trabajos digitales realizados fueron los propios estudiantes, a quienes GS les permitió ejercitarse en la indagaban y acceder a la alfabetización científica y tecnológica.

La plataforma se diseñó para que los estudiantes tuvieran acceso y pudieran editar los contenidos. De esta forma fueron capaces de crear una wiki, a partir de una pregunta generadora o un tema que dieron lugar a un producto de su interés durante la sesión. Se les permitió el diseño, construcción y edición de la misma; desarrollaron un portafolio digital donde publicaron sus producciones. Mediante la búsqueda de información y el uso de herramientas digitales almacenaron y contribuyeron en la conformación de un portafolio, que además les sirvió como archivador digital; en este insertaron sus archivos personales, que podían ser descargados y leídos directamente por todos los estudiantes. Esto facilitó la evaluación por parte del docente. En el caso de los videos, estos podían verse tantas veces como los estudiantes lo necesitaran.

El diseño y elaboración de los diferentes productos, más allá de la inversión de tiempo y esfuerzo adicionales, fue una experiencia satisfactoria y gratificante tanto para el mediador como para los estudiantes. Estos últimos fueron conscientes de la mejora de sus aprendizajes como resultado su compromiso y empoderamiento.

Concluida la fase de estímulo con la variable independiente, se administró el post test de la prueba de CTA. En esta segunda etapa los estudiantes realizaron en forma individual o grupal una serie de actividades y productos en los que se veía reflejado el trabajo con la variable Google Sites.

Fase de análisis. Se prepararon las bases de datos de las mediciones en pre test y post test a los dos 
Google Sites como herramienta didáctica online en el aprendizaje significativo del área de ciencia, tecnología y ambiente en estudiantes de cuarto grado de educación secundaria

grupos de la muestra. Se realizó el análisis para la descripción comparativa de resultados y el análisis estadístico inferencial recurriendo al método hipotético-deductivo para el contraste de las hipótesis de investigación.

Fase de reporte de resultados. Se redactó el informe de la investigación considerando las pautas señaladas en el protocolo institucional y el Manual de Publicaciones (American Psychological Association, 2010). El trabajo final cumplió con todas las exigencias formales, garantizó la reserva de la identidad de los individuos comprendidos en la muestra y respetó el derecho de autor.

Métodos y técnicas de análisis de datos.

Los métodos utilizados fueron el analítico, sintético, comparativo y el hipotético deductivo. Este último implicó someter a contraste las hipótesis de investigación para verificar si el uso de Google Sites influye o no en el aprendizaje significativo de CTA (Hernández \& Mendoza, 2018). Se analizaron los resultados de las mediciones pre test y post test a los grupos de control y experimental y los resultados sirvieron para arribar a las conclusiones del estudio. La técnica empleada es el análisis estadístico, con ayuda del software estadístico SPSS v.22, para calcular las medidas estadísticas: media, mediana, desviación estándar y rango promedio. En el análisis inferencial se utilizó la prueba de Kruskal-Wallis, debido a que no todos los datos tenían una distribución normal (Rial \& Valera, 2008). Los resultados se presentan en tablas (muestran comparativamente las medidas estadísticas y los resultados del contraste de hipótesis) y el diagrama de caja y bigotes (compara la mediana del pre test $y$ post test).

\section{Confidencialidad}

La investigación se desarrolló con respeto estricto de la identidad de los estudiantes comprendidos en la muestra y con la autorización expresa de los padres de familia y el conocimiento de las autoridades de la institución educativa. A los padres de familia se les garantizó que los resultados de las evaluaciones se manejarían de forma anónima y con absoluta reserva de los resultados individuales (American Psychological Association, 2010).

\section{Resultados}

La verificación de las hipótesis se hizo empleando la Prueba U de Mann Whitney. La decisión se tomó considerando un nivel de significancia de 0.05 ( $5 \%$ de error). Por consiguiente: Si $p>0.05$, se concluye con la hipótesis nula $(\mathrm{H} 0)$ y si $p<$ 0.05 , se concluye con la hipótesis alterna $(\mathrm{H} 1)$.

Prueba de hipótesis para el efecto de Google Sites como herramienta didáctica online en el aprendizaje significativo en el área de Ciencia, Tecnología y Ambiente

\section{Hipótesis general}

Ha. Google Sites como herramienta didáctica online influye significativamente en el aprendizaje significativo en el área de Ciencia, Tecnología y Ambiente en estudiantes del cuarto grado del nivel secundaria de la Institución Educativa Publica No 3056 "Gran Bretaña” - Lima.

H0. Google Sites como herramienta didáctica online no influye significativamente en el aprendizaje significativo en el área de Ciencia, Tecnología y Ambiente en estudiantes del cuarto grado del nivel secundaria de la Institución Educativa Publica No 3056 "Gran Bretaña” - Lima.

En el pre test de la variable aprendizaje significativo en el área de Ciencia, Tecnología y Ambiente (tabla 5) la media del grupo de control fue ligeramente mayor $(7.32+2.918)$ que la del grupo experimental $(5.83+1.810)$; mientras que en el post test, la media del grupo experimental (11.21 + 2.284) superó en 3.26 puntos a la media del grupo de control $(7.95+2.903)$.

Los resultados de la prueba de Kruskal-Wallis indicaron que en el pre test de la variable aprendizaje significativo en el área de Ciencia, Tecnología y Ambiente hubo diferencias significativas entre los grupos de control y experimental, pero a favor del primero. Sin embargo, en el post test el grupo experimental obtuvo mejores resultados y la diferencia fue significativa $(p=.000)$ a favor de este. Por tanto, al 0.000 de error, se concluye que Google Sites como herramienta didáctica online influye significativamente en el aprendizaje significativo en el área de CTA. 


\section{Tabla 4}

Medidas estadísticas de la variable aprendizaje significativo en el área de Ciencia, Tecnología y Ambiente en los grupos de control y experimental, pre test y post test.

\begin{tabular}{|c|c|c|c|c|c|}
\hline \multirow[b]{3}{*}{ Fase } & \multirow[b]{3}{*}{ Estadígrafo } & \multicolumn{4}{|c|}{$\begin{array}{l}\text { Aprendizaje significativo en el área } \\
\text { de Ciencia, Tecnología y Ambiente }\end{array}$} \\
\hline & & \multirow[b]{2}{*}{$\begin{array}{l}\text { Grupo } \\
\text { de } \\
\text { control }\end{array}$} & \multirow[b]{2}{*}{$\begin{array}{c}\text { Grupo } \\
\text { Experi- } \\
\text { mental }\end{array}$} & \multicolumn{2}{|c|}{ Kruskal-Wallis } \\
\hline & & & & $\begin{array}{l}\text { Chi- } \\
\text { Cua- } \\
\text { drado }\end{array}$ & $\begin{array}{l}p- \\
\text { valor }\end{array}$ \\
\hline \multirow{4}{*}{$\begin{array}{l}\text { Pre test } \\
p>.05\end{array}$} & Media & 7.32 & 5.83 & 2.956 & .086 \\
\hline & Mediana & 7.50 & 6.00 & & \\
\hline & Desv. típ. & 2.918 & 1.810 & & \\
\hline & Rango prom. & 27.02 & 20.27 & & \\
\hline \multirow{4}{*}{$\begin{array}{l}\text { Post test } \\
p<.01\end{array}$} & Media & 7.95 & 11.21 & 12.956 & .000 \\
\hline & Mediana & 7.50 & 11.50 & & \\
\hline & Desv. típ. & 2.903 & 2.284 & & \\
\hline & Rango prom. & 16.11 & 30.27 & & \\
\hline $\mathrm{N}$ & & 22 & 24 & & \\
\hline
\end{tabular}

Fuente: Base de datos de la prueba diagnóstica regional 2017, área de Ciencia, Tecnología y Ambiente (CTA) para estudiantes del cuarto grado de educación secundaria de menores.

Según la tabla 4 y figura 6, en el pre test de la variable aprendizaje significativo en el área de Ciencia, Tecnología y Ambiente, el grupo de control obtuvo una mediana mayor (7.5) a la del grupo experimental (6). Sin embargo, en el post test, la mediana del grupo experimental (11.5) superó en 4 puntos a la mediana del grupo de control (7.5).

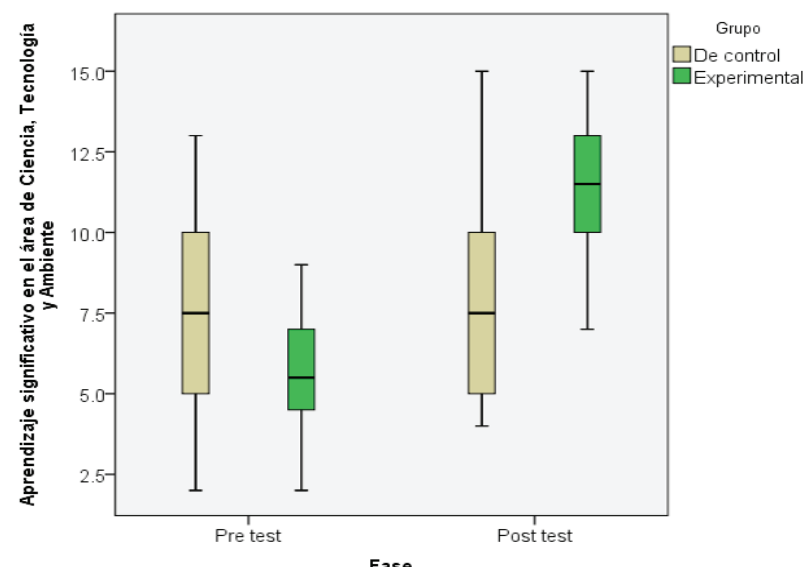

Figura 2

Diagrama de dispersión para la diferencia en el aprendizaje significativo en el área de CTA entre los grupos de control y experimental, pre test $\mathrm{y}$ post test.
Prueba de hipótesis para el efecto de Google Sites en la competencia indaga mediante métodos científicos en situaciones que pueden ser investigadas por la ciencia

\section{Hipótesis especifica 1}

Ha1. Google Sites como herramienta didáctica online influye significativamente en la competencia indaga mediante métodos científicos en situaciones que pueden ser investigadas por la ciencia.

H0. Google Sites como herramienta didáctica online no influye significativamente en la competencia indaga mediante métodos científicos en situaciones que pueden ser investigadas por la ciencia.

En el pre test de la competencia indaga mediante métodos científicos (tabla 6), situaciones que pueden ser investigadas por la ciencia, la media del grupo de control $(2.64+1.177)$ fue bastante similar a la del grupo experimental $(2.25+.676)$; pero en el post test, la media del grupo experimental $(4.00+.885)$ fue 1.18 puntos más que la media del grupo de control $(2.82+1.368)$.

La prueba U de Mann Whitney indicó que, en el pre test de la competencia indaga mediante métodos científicos, no hubo diferencias significativas entre los grupos de control y experimental. En cambio, en el post test, el grupo experimental superó significativamente $(p=.001)$ al grupo de control. Por tanto, al 0.001 de error se concluye que Google Sites como herramienta didáctica online influye significativamente en la competencia indaga mediante métodos científicos en situaciones que pueden ser investigadas por la ciencia.

\section{Tabla 6}

Medidas estadísticas de la competencia indaga mediante métodos científicos en los grupos de control y experimental, pre test y post test.

\begin{tabular}{|c|c|c|c|c|c|}
\hline \multirow[b]{3}{*}{ Fase } & \multirow[b]{3}{*}{ Estadígrafo } & \multicolumn{4}{|c|}{$\begin{array}{l}\text { Indaga mediante métodos } \\
\text { científicos }\end{array}$} \\
\hline & & \multirow[b]{2}{*}{$\begin{array}{c}\text { Grupo } \\
\text { de } \\
\text { control }\end{array}$} & \multirow[b]{2}{*}{$\begin{array}{l}\text { Grupo } \\
\text { Experi- } \\
\text { mental }\end{array}$} & \multicolumn{2}{|c|}{ Kruskal-Wallis } \\
\hline & & & & $\begin{array}{l}\text { Chi- } \\
\text { Cua- } \\
\text { drado }\end{array}$ & $\begin{array}{c}p- \\
\text { valor }\end{array}$ \\
\hline \multirow{3}{*}{$\begin{array}{l}\text { Pre test } \\
p>.05\end{array}$} & Media & 2.64 & 2.25 & 2.956 & .086 \\
\hline & Desv. típ. & 1.177 & .676 & & \\
\hline & Rango prom. & 26.02 & 21.19 & & \\
\hline
\end{tabular}


Google Sites como herramienta didáctica online en el aprendizaje significativo del área de ciencia, tecnología y ambiente en estudiantes de cuarto grado de educación secundaria

\begin{tabular}{|c|c|c|c|c|c|}
\hline \multirow[b]{3}{*}{ Fase } & \multirow[b]{3}{*}{ Estadígrafo } & \multicolumn{4}{|c|}{$\begin{array}{l}\text { Indaga mediante métodos } \\
\text { científicos }\end{array}$} \\
\hline & & \multirow[b]{2}{*}{$\begin{array}{l}\text { Grupo } \\
\text { de } \\
\text { control }\end{array}$} & \multirow[b]{2}{*}{$\begin{array}{c}\text { Grupo } \\
\text { Experi- } \\
\text { mental }\end{array}$} & \multicolumn{2}{|c|}{ Kruskal-Wallis } \\
\hline & & & & $\begin{array}{l}\text { Chi- } \\
\text { Cua- } \\
\text { drado }\end{array}$ & $\begin{array}{c}p- \\
\text { valor }\end{array}$ \\
\hline \multirow{3}{*}{$\begin{array}{l}\text { Post test } \\
p<.01\end{array}$} & Media & 2.82 & 4.00 & 10.348 & .001 \\
\hline & Desv. típ. & 1.368 & .885 & & \\
\hline & Rango prom. & 17.09 & 29.38 & & \\
\hline $\mathrm{N}$ & & 22 & 24 & & \\
\hline
\end{tabular}

Fuente: Base de datos de la prueba diagnóstica regional 2017, área de Ciencia, Tecnología y Ambiente (CTA) para estudiantes del cuarto grado de educación secundaria de menores.

Prueba de hipótesis para el efecto de Google Sites en la competencia explica el mundo físico, basado en conocimientos científicos

\section{Hipótesis especifica 2}

Ha2. Google Sites como herramienta didáctica online influye significativamente en la competencia explica el mundo físico, basado en conocimientos científicos.

H0. Google Sites como herramienta didáctica online no influye significativamente en la competencia explica el mundo físico, basado en conocimientos científicos.

En el pre test de la competencia explica el mundo físico (tabla 7) la media del grupo de control $(2.59+1.297)$ fue ligeramente mayor que la del grupo experimental $(1.92+1.100)$; pero en el post test, la media del grupo experimental (3.5 +1.022 ) fue mayor 0.82 más que la media del grupo de control $(2.68+1.129)$.

La prueba de Kruskal-Wallis indicó en el pre test de la competencia explica el mundo físico hubo diferencias significativas $(p=.053)$ entre los grupos de control y experimental, a favor del primero. Por el contrario, en el post test, el grupo experimental superó significativamente $(p=.015)$ al grupo de control. Por tanto, al 0.015 de error se concluye que Google Sites como herramienta didáctica online influye significativamente en la competencia explica el mundo físico, basado en conocimientos científicos.

\section{Tabla 7}

Medidas estadísticas de la competencia explica el mundo físico en los grupos de control y experimental, pre test y post test.

\begin{tabular}{|c|c|c|c|c|c|}
\hline \multirow[b]{3}{*}{ Fase } & \multirow[b]{3}{*}{ Estadígrafo } & \multicolumn{4}{|c|}{ Explica el mundo físico } \\
\hline & & \multirow[b]{2}{*}{$\begin{array}{l}\text { Grupo } \\
\text { de } \\
\text { control }\end{array}$} & \multirow[b]{2}{*}{$\begin{array}{l}\text { Grupo } \\
\text { Experi- } \\
\text { mental }\end{array}$} & \multicolumn{2}{|c|}{ Kruskal-Wallis } \\
\hline & & & & $\begin{array}{l}\text { Chi- } \\
\text { Cua- } \\
\text { drado }\end{array}$ & $\begin{array}{c}p- \\
\text { valor }\end{array}$ \\
\hline \multirow{3}{*}{$\begin{array}{l}\text { Pre test } \\
p>.05\end{array}$} & Media & 2.59 & 1.96 & 3.729 & .053 \\
\hline & Desv. típ. & 1.297 & 1.083 & & \\
\hline & Rango prom. & 27.30 & 20.02 & & \\
\hline \multirow{3}{*}{$\begin{array}{l}\text { Post test } \\
p<.01\end{array}$} & Media & 2.68 & 3.50 & 5.906 & .015 \\
\hline & Desv. típ. & 1.129 & 1.022 & & \\
\hline & Rango prom. & 18.64 & 27.96 & & \\
\hline $\mathrm{N}$ & & 22 & 24 & & \\
\hline
\end{tabular}

Fuente: Base de datos de la prueba diagnóstica regional 2017, área de Ciencia, Tecnología y Ambiente (CTA) para estudiantes del cuarto grado de educación secundaria de menores.

Prueba de hipótesis para el efecto de Google Sites en la competencia diseńa y produce prototipos tecnológicos para resolver problemas de su entorno

\section{Hipótesis especifica 3}

Ha3. Google Sites como herramienta didáctica online influye significativamente en la competencia diseńa y produce prototipos tecnológicos para resolver problemas de su entorno.

H0. Google Sites como herramienta didáctica online no influye significativamente en la competencia diseña y produce prototipos tecnológicos para resolver problemas de su entorno.

En el pre test de la competencia diseña y produce prototipos tecnológicos para resolver problemas de su entorno (tabla 8), la media del grupo de control $(1.59+.959)$ fue mayor que la del grupo experimental $(1.25+.944)$; pero en el post test, la media del grupo experimental $(2.63+.647)$ fue 0.72 puntos más que la media del grupo de control $(1.91+.750)$.

La prueba de Kruskal-Wallis indicó que en el pre test de la competencia diseña y produce prototipos tecnológicos no hubo diferencias significativas entre los grupos de control y experimental. 
Pero en el post test, el grupo experimental superó significativamente $(p=.001)$ al grupo de control. Por tanto, al 0.001 de error, se concluye que Google Sites como herramienta didáctica online influye significativamente en la competencia diseña y produce prototipos tecnológicos para resolver problemas de su entorno.

\section{Tabla 8}

Medidas estadísticas de la competencia diseña y produce prototipos tecnológicos en los grupos de control y experimental, pre test y post test.

\begin{tabular}{|c|c|c|c|c|c|}
\hline \multirow[b]{3}{*}{ Fase } & \multirow[b]{3}{*}{ Estadígrafo } & \multicolumn{4}{|c|}{$\begin{array}{c}\text { Diseña y produce prototipos } \\
\text { tecnológicos }\end{array}$} \\
\hline & & \multirow[b]{2}{*}{$\begin{array}{l}\text { Grupo } \\
\text { de } \\
\text { control }\end{array}$} & \multirow[b]{2}{*}{$\begin{array}{l}\text { Grupo } \\
\text { Experi- } \\
\text { mental }\end{array}$} & \multicolumn{2}{|c|}{ Kruskal-Wallis } \\
\hline & & & & $\begin{array}{l}\text { Chi- } \\
\text { Cua- } \\
\text { drado }\end{array}$ & $\begin{array}{c}p \text { - } \\
\text { valor }\end{array}$ \\
\hline \multirow{3}{*}{$\begin{array}{l}\text { Pre test } \\
p>.05\end{array}$} & Media & 1.59 & 1.25 & 2.154 & .142 \\
\hline & Desv. típ. & .959 & .944 & & \\
\hline & Rango prom. & 26.36 & 20.88 & & \\
\hline \multirow{3}{*}{$\begin{array}{l}\text { Post test } \\
p<.01\end{array}$} & Media & 1.91 & 2.63 & 11.105 & .001 \\
\hline & Desv. típ. & .750 & .647 & & \\
\hline & Rango prom. & 17.11 & 29.35 & & \\
\hline $\mathrm{N}$ & & 22 & 24 & & \\
\hline
\end{tabular}

Fuente: Base de datos de la prueba diagnóstica regional 2017, área de Ciencia, Tecnología y Ambiente (CTA) para estudiantes del cuarto grado de educación secundaria de menores.

Prueba de hipótesis para el efecto de Google Sites en la competencia construye una posición crítica sobre la ciencia y la tecnología en sociedad

\section{Hipótesis especifica 4}

Ha4. Google Sites como herramienta didáctica online influye significativamente en la competencia construye una posición crítica sobre la ciencia y la tecnología en sociedad.

H0. Google Sites como herramienta didáctica online no influye significativamente en la competencia construye una posición crítica sobre la ciencia y la tecnología en sociedad.

En el pre test de la competencia construye una posición crítica sobre la ciencia y la tecnología en sociedad (tabla 9), la media del grupo de control $(.50+.512)$ fue menor que la del grupo experimental $(.55+.510)$; pero en el post test, la me- dia del grupo experimental $(1.08+.776)$ fue 0.7 puntos mayor que la media del grupo de control $(.38+.495)$.

Los resultados de la prueba de Kruskal-Wallis indicaron que en el pre test de la competencia construye una posición crítica sobre la ciencia y la tecnología en sociedad no hubo diferencias significativas entre los grupos de control y experimental. Pero en el post test, el grupo experimental superó también significativamente $(p=.015)$ al grupo de control. Por tanto, al 0.015 de error, se concluye que Google Sites como herramienta didáctica online influye significativamente en la competencia construye una posición crítica sobre la ciencia y la tecnología en sociedad.

\section{Tabla 9}

Medidas estadísticas de la competencia construye una posición crítica sobre la ciencia y la tecnología en sociedad en los grupos de control y experimental, pre test y post test.

\begin{tabular}{|c|c|c|c|c|c|}
\hline \multirow[b]{3}{*}{ Fase } & \multirow[b]{3}{*}{ Estadígrafo } & \multicolumn{4}{|c|}{$\begin{array}{l}\text { Construye una posición crítica } \\
\text { sobre la ciencia y la tecnología en } \\
\text { sociedad }\end{array}$} \\
\hline & & \multirow[b]{2}{*}{$\begin{array}{l}\text { Grupo } \\
\text { de } \\
\text { control }\end{array}$} & \multirow[b]{2}{*}{$\begin{array}{l}\text { Grupo } \\
\text { Experi- } \\
\text { mental }\end{array}$} & \multicolumn{2}{|c|}{ Kruskal-Wallis } \\
\hline & & & & $\begin{array}{l}\text { Chi- } \\
\text { Cua- } \\
\text { drado }\end{array}$ & $\begin{array}{c}p- \\
\text { valor }\end{array}$ \\
\hline \multirow{3}{*}{$\begin{array}{l}\text { Pre test } \\
p>.05\end{array}$} & Media & .50 & .55 & .714 & .398 \\
\hline & Desv. típ. & .512 & .510 & & \\
\hline & Rango prom. & 25.00 & 22.13 & & \\
\hline \multirow{3}{*}{$\begin{array}{l}\text { Post test } \\
p<.01\end{array}$} & Media & .38 & 1.08 & 5.963 & .015 \\
\hline & Desv. típ. & .495 & .776 & & \\
\hline & Rango prom. & 18.86 & 27.75 & & \\
\hline $\mathrm{N}$ & & 22 & 24 & & \\
\hline
\end{tabular}

Fuente: Base de datos de la prueba diagnóstica regional 2017, área de Ciencia, Tecnología y Ambiente (CTA) para estudiantes del cuarto grado de educación secundaria de menores.

\section{Discusión y Conclusiones}

Los resultados del contraste de la hipótesis general demostraron que, en el post test, hubo diferencias significativas entre los estudiantes del grupo experimental y de control. El Google Sites como herramienta didáctica online influye significativamente $(p=.000)$ en el aprendizaje significativo del área de CTA. Algo similar estableció en Espa- 
Google Sites como herramienta didáctica online en el aprendizaje significativo del área de ciencia, tecnología y ambiente en estudiantes de cuarto grado de educación secundaria

ña Bassas (2013), al utilizar Google Sites para la enseñanza del álgebra a estudiantes con trastornos de déficit de atención e hiperactividad (TDAH). Demostró que el uso de Google Sites mejora el nivel de concentración de los estudiantes, aunque reconoció que no pudo profundizar para averiguar si esta herramienta mejoraba el aprendizaje. En Perú, Alarcón, Ramírez \& Vílchez (2014) también obtuvieron un efecto similar al analizar la relación entre las TIC y el aprendizaje del idioma inglés con estudiantes universitarios de la especialidad ingles - francés, pues verificaron que existe correlación directa entre estas variables, en especial entre los audiovisuales y el aprendizaje significativo de dicho idioma. En España, Acosta, Martín \& Hernández (2015), trabajaron con Google Sites en la aplicación de un modelo de webquest para la enseñanza de geografía en educación secundaria, en donde comprobaron que las herramientas Geoquest y Eartquest son excelentes para mejorar el aprendizaje de geografía. Es preciso resaltar que gran parte del logro de los resultados alcanzados en torno a los aprendizajes significativos se debe a la incorporación de herramientas tecnológicas en el proceso de aprendizaje. En los estudios mencionados se advierte que la aplicación de las TIC en la enseñanza requiere de docentes preparados, capaces de guiar a los estudiantes en el uso eficiente de dichos recursos para la solución de las dificultades que surjan en el proceso de aprendizaje. De forma similar, la presente investigación determinó la influencia del Google Sites como herramienta didáctica online para el aprendizaje significativo en el área de CTA con estudiantes del cuarto grado de educación secundaria de la Institución Educativa Publica No 3056 “Gran Bretaña”. Quiere decir que, utilizada pedagógicamente, Google Sites es una aplicación online que se ha convertido en herramienta didáctica útil para el docente (Barret, 2014). Facilita la enseñanza y mejora los procesos de aprendizaje.

La prueba de hipótesis indicó que, en el post test, la diferencia entre el grupo experimental y de control fue significativa $(p=0.001)$. Los estudiantes mejoraron su aprendizaje en la competencia indaga mediante métodos científicos, siendo capaces de indagar de manera autónoma, identificaron problemas, plantearon preguntas y diseñaron e implementaron estrategias para dar respuesta a sus interrogantes; también analizaron información y reflexionaron sobre la validez de la respuesta obtenida; crearon actividades orientadas a este propósito. Monsalve (2011), en Colombia, dio con un hallazgo semejante, al implementar las herramientas TIC como estrategia didáctica para generar un aprendizaje significativo en estudiantes de sexto grado. Consiguió que los estudiantes se involucren en la indagación científica con ayuda de videos e imágenes interactivas, consultando páginas web y realizando actividades en la sala de informática o desde la casa. También Meléndez (2013), en Lima, llegó a la conclusión de que el uso de la Webquest como recurso mejora la capacidad de comprensión de la información, indagación, experimentación y juicio crítico en estudiantes de quinto grado de educación secundaria. Comprobó que la Webquest, como Google Site, favorece la indagación científica; los estudiantes, además de diseñar estrategias para indagar, generan y registran información, la analizan, evalúan y comunican sus hallazgos.

Según los resultados, en el post test, hubo diferencias significativas $(p=0.015)$ entre el grupo experimental y el grupo de control. En la influencia del Google Sites como herramienta didáctica online en la competencia explica el mundo físico, basado en conocimientos científicos; resultados que se relacionan con los hallazgos de Rodríguez (2016), quien en Santiago de Chucos comprobó que un taller de prototipos tecnológicos influye significativamente $(p<0.01)$ en la competencia explica el mundo físico. Dicho de otro modo, las TIC optimizan el desarrollo de esta competencia. Es preciso destacar que los estudiantes, al explicar científicamente los fenómenos, utilizan conocimientos apropiados para generar hipótesis explicativas en situaciones determinadas en las que no hay conocimientos o datos. Comprenden los conocimientos científicos a partir de sus conocimientos previos sobre el mundo; pueden explicar los fenómenos y resolver situaciones problemáticas de la realidad. Son capaces de conocer, contrastar y comparar los conocimientos alcanzados por los diversos pueblos a lo largo del tiempo y el espacio; construyen argumentos, deliberan, toman decisiones a nivel personal y público, buscan mejorar su calidad de vida y también se interesan por conservar el ambiente (Ministerio de Educa- 
ción de Perú, 2015b, 2015c, 2017).

Con relación a la influencia del Google Sites como herramienta didáctica online en la competencia diseña y produce prototipos tecnológicos para resolver problemas de su entorno, los resultados evidenciaron que, en el post test, hubo diferencias significativas $(p=0.001)$ entre el grupo experimental y el grupo de control. De acuerdo a estos resultados, se corrobora los postulados teóricos que sustentan a la competencia mencionada. Luego del estímulo, los estudiantes diseñaron y construyeron objetos o sistemas basados en conocimientos científicos y tecnológicos, es decir, usaron en forma práctica la tecnología para resolver problemas del contexto y transformar la realidad. De ahí que el logro de esta competencia supone que los estudiantes determinen, diseñen, implementen una alternativa de solución y evalúen y comuniquen los resultados de su funcionamiento, así como los impactos de esta (Ministerio de Educación de Perú, 2015c, 2017). En otras palabras: los estudiantes deben saber aplicar conocimientos básicos y procedimientos en la solución de problemas de su entorno (UNESCO, 2016).

La influencia del Google Sites como herramienta didáctica online en la competencia construye una posición crítica sobre la ciencia y la tecnología en sociedad. Los resultados mostraron que, en el post test, también hubo diferencias significativas $(\mathrm{p}=$ 0.000) entre el grupo experimental y el grupo de control. Este hallazgo se relaciona con el trabajo de Meléndez (2013), quien al estudiar en Lima a la Webquest como recurso de motivación para el aprendizaje de los temas de ciencias con estudiantes del quinto grado de secundaria, comprobó el impacto de esta en la capacidad de juicio crítico; es decir, esta herramienta permite a los estudiantes construir una postura autónoma y crítica frente a situaciones sociocientíficas. A partir de estas situaciones, los estudiantes están en condiciones de participar, deliberar y tomar decisiones en asuntos personales y públicos relacionados con la ciencia y la tecnología (Ministerio de Educación de Perú, 2015c).

Está claro que las TIC favorecen el logro de aprendizajes significativos, siempre y cuando los docentes elijan y utilicen las herramientas que se adapten mejor a las necesidades de cada proceso de aprendizaje (Rojas, 2017). El reto radica en saber integrarlas a las actividades académicas para motivar el entusiasmo de los educandos (Hernández, Gómez \& Balderas, 2014) y conseguir que estos adopten una postura crítica frente a las herramientas tecnológicas que decidan utilizar en su proceso de aprendizaje.

Google Sites es una herramienta de la que pueden disponer libremente los docentes para plantear a los estudiantes actividades atractivas e interesantes que los motiven a involucrarse en el proceso de aprendizaje. Si se pretende que estos logren aprendizajes significativos en alguna materia, las actividades de aprendizaje requieren de estrategias, herramientas y materiales novedosos que propicien la innovación, la creatividad y el desarrollo del pensamiento crítico.

El uso de las TIC, tanto como material concreto y el interactivo, fortalece la labor docente y el trabajo realizado por los estudiantes. Estas herramientas favorecen aprendizajes significativos, pero es necesario que los docentes sepan elegir las herramientas que utilizarán y las adapten a las necesidades de cada proceso de aprendizaje. La correcta integración de las Tic en el proceso de aprendizaje reclama nuevas competencias en los docentes y también mayor responsabilidad de los estudiantes para sujetarse a las reglas de participación en las actividades didácticas propuestas por aquel.

La claridad de los objetivos propuestos en una actividad de aprendizaje orienta la selección de herramientas tecnológicas pertinentes y señala las pautas precisas para la integración de estas en el proceso de aprendizaje. Las actividades en el aula se convierten en novedosas; despiertan el interés de los estudiantes, les dan suficiente espacio para la creatividad y estimulan su participación entusiasta en los retos que plantea el docente.

\section{REFERENCIAS BIBLIOGRÁFICAS}

Acosta, R., Martín, A.V. \& Hernández, A. (2015). Propuesta de un modelo de webquest para la enseńanza de geografía en educación secundaria con la aplicación de google sites. Edutec. Revista Electrónica de Tecnología Educativa, [S.1.], 
Google Sites como herramienta didáctica online en el aprendizaje significativo del área de ciencia, tecnología y ambiente en estudiantes de cuarto grado de educación secundaria

n. 52, p. a302, jun. 2015. ISSN 1135-9250. Recuperado de http://www.edutec.es/revista/index.php/edutec-e/article/ view/296

Alarcón, D., Ramírez, M. \& Vílchez, M. (2014). Las tecnologías de la información y comunicación (TIC) y su relación con el aprendizaje del inglés en los estudiantes de la especialidad de inglés - francés, promoción 2011 de la Universidad Enrique Guzmán y Valle. (Tesis de Licenciatura inédita). Universidad Nacional Enrique Guzmán y Valle: Lima. Recuperado de: http://repositorio.une.edu.pe/bitstream/ handle/UNE/700/T025_09580299_T.pdf?sequence=18isAllowed $=\mathrm{y}$.

Ambròs, A. \& Ramos. J.C. (2017). El uso didáctico de Google Sites en la construcción compartida del conocimiento. Resed, Revista de Estudios Socioeducativos, Nro. 5, pp. 63-74. https://doi.org/10.25267/Rev_estud_socioeducativos.2017.i5.07

American Psychological Association. (2010). Manual de publicaciones de la American Psychological Association (3a ed.) México: El Manual Moderno.

Aubry, C. (2012). Cree su primer sitio web. Del dise-o a la realización. Barcelona: ENI.

Azamar-Alonso, A. (2015). El modelo educativo en México: una revisión de su alcance y una perspectiva para el futuro. Rastros Rostros 17.31: 127-141. http://dx.doi. org/10.16925/ra.v17i31.1094

Barrett, H. C. (2014). ePortfolio Mash Up with GoogleApps. Recuperado de: ePortfolio Mash Up with GoogleApps: http://electronicportfolios.com/google/index.html

Bassas, M. (2013). Uso del Google Sites como herramienta para la enseñanza de álgebra a alumnos con TDAH en el $2^{\circ}$ de la ESO. (Tesis de maestría inédita, Universidad Internacional de la Rioja: Barcelona). Recuperada de http://reunir. unir.net/bitstream/handle/123456789/1801/2013_04_09_ Tfm_Estudio_Del_Trabajo.pdf?sequence=1 2 isAllowed $=y$.

Caamaño, E., Cañal, P. \& De Pro, A. (2012). 11 Ideas clave. El desarrollo de la competencia científica. Barcelona: Graó.

Cacheiro, M.L., Sánchez, C. \& González, J.M (coords.). (2015). Recursos tecnológicos en contextos educativos. Madrid: UNED.

Ampos, E. (2014). Las Metodologías tradicionales de enseñanza desde la perspectiva de los familiares y docentes del Colegio Andolina. (Tesis de licenciatura inédita, Universidad Internacional de La Rioja, España). Recuperada de: https://reunir.unir.net/bitstream/handle/123456789/2236/ Campos-Gutierrez.pdf

Centro Nacional de Planeamiento Estratégico -CEPLAN. (2014). La educación del futuro y el futuro de la educación. Lima: Punto \& Grafía.

Colás, M.P., De Pablos, J. \& Ballesta, J. (2018). Incidencia de las TIC en la enseñanza en el sistema educativo español: una revisión de la investigación. RED. Revista de Educación a Distancia. Núm. 56, Artic. 2, 32-01-2018 https://doi.org/10.6018/red/56/2
Fórez-Nisperuza, E. \& De la Ossa, A.F. (2018). La indagación científica y la transmisión-recepción: una contrastación de modelos de enseńanza para el aprendizaje del concepto densidad. Revista Científica, 31(1), 55-67.

https://doi.org/10.14483/23448350.12452

Garmendia, M. \& Guisasola, J. (2015). Alfabetización científica en contextos escolares: El Proyecto Zientzia Live! Revista Eureka sobre Enseńanza y Divulgación de las Ciencias, 12(2), 294-310.

https://doi.org/10.25267/Rev_Eureka_ensen_divulg_ cienc.2015.v12.i2.05

González, J. (2014). Princippia. Aprendiendo y ense-ando con tecnología. Recuperado de: Princippia. Aprendiendo y enseñando con tecnología. Recuperado de http://blog.princippia.com/2014/04/ideas-y-pautas-para-usar-google-sites. html

González-Weil, C., Cortez, M., Bravo, P., Ibaceta, Y., Cuevas, K., Quiñones, P. et al. (2012). La indagación científica como enfoque pedagógico: estudio sobre las prácticas innovadoras de docentes de ciencia en EM. Estudios Pedagógicos, 38 (2), 85-102. Recuperado de https://doi.org/10.4067/S0718-07052012000200006

Hernández, R.M. (2017). Impacto de las Tic en la educación: Retos y Perspectivas. Propósitos y Representaciones, 5(1), 325-347.

https://doi.org/10.20511/pyr2017.v5n1.149

Hernández, C.A., Gómez, M.G. \& Balderas, M. (2014). Inclusión de las tecnologías para facilitar los procesos de enseñanza - aprendizaje en ciencias naturales. Revista Electrónica "Actualidades Investigativas en Educación", 14 (3), 1-19. Recuperado de http://www.redalyc.org/ pdf/447/44732048010.pdf

Hernández, R. \& Mendoza, C.P. (2018). Metodología de la Investigación. México: McGraw-Hill. https://doi. org/10.17993/CcyLl.2018.15

Meléndez, M. (2013). La Webquest como un recurso de motivación para el aprendizaje de los temas de Ciencias en estudiantes del quinto grado de secundaria de un colegio del Cercado de Lima. (Tesis de licenciatura inédita) Pontifica Universidad Católica del Perú: Lima. Recuperado de http://tesis.pucp.edu.pe/repositorio/bitstream/handle/123456789/5146/Melendez_Campos_Melvin_Webquest_Colegio.pdf?sequence $=1$.

Ministerio de Educación del Perú. (2004). Guía de Evaluación del Aprendizaje. Lima: MINEDU.

Ministerio de Educación del Perú. (2012). Marco del Buen Desempeño Docente. Lima: MINEDU.

Miinisterio de Educación de Perú. (2013). Rutas del Aprendizaje: Ciencia y Tecnología. Fascículo general. Lima: Cimagraf.

Ministerio de Educación de Perú. (2015a). Ciencia, Tecnología y Ambiente 4º. Manual para el docente. Lima: Santillana.

Ministerio de Educación de Perú. (2015b). La competencia científica en el marco de Pisa 2015. Lima: MINEDU. 
Ministerio de Educación. (2015c). Rutas del Aprendizaje. Ciencia, Tecnología y Ambiente VII Ciclo. Lima: Quad/ Graphics Perú S.A.

Ministerio de Educación de Perú. (2017). Currículo Nacional de la Educación Básica. Lima: MINEDU.

Monsalve, M. (2011). Implementación de las TICS como estrategia didáctica para generar un aprendizaje significativo de los procesos celulares en los estudiantes de grado sexto de la Institución educativa San Andrés del Municipio de Girardota. (Tesis de Maestría inédita) Universidad nacional de Colombia - Sede Medellín: Colombia. Recuperado de http://www.bdigital.unal.edu.co/5936/1/43666105.2012. pdf.

Palacio, M. \& Cabrera, K. (2017). La gobernanza de internet como plataforma para impulsar políticas en la educación con TIC. El caso de Colombia. OPERA, (21), 5-23.

https://doi.org/10.18601/16578651.n21.02

Ramos, A. \& Ramos, M.J. (2011). Aplicaciones web. Madrid: Paraninfo.

Rial, A. \& Valera, J. (2008). Estadística práctica para la investigación en ciencias de la salud. La Coruña: Netbiblo.

Rojas, M. (2017) Los recursos tecnológicos como soporte para la enseńanza de las ciencias naturales. Hamut'ay, 4 (1), 85-95. https://doi.org/10.21503/hamu.v4i1.1403

Rodríguez, F.M. (2016). Taller de Prototipos tecnológicos para optimizar la competencia explica el mundo físico del área de Ciencia y Ambiente en estudiantes del sexto grado del distrito de Santiago de Chuco, 2016. (Tesis doctoral inédita). Universidad César Vallejo: Trujillo.

Turpo, O. (2016). El currículo de la competencia científica en Perú y Portugal. Comuni@cción, 7(2), 15-26. Recuperado de http://www.scielo.org.pe/scielo.php?script=sci_arttext\&pid=S2219-71682016000200002\&lng=es\&tlng=es

UNESCO. (2013). Enfoques estratégicos sobre las TICS en Educación en América Latina y el Caribe. Santiago de Chile: OREALC.

UNESCO. (2014). Enseñanza y Aprendizaje: Lograr la calidad para todos. Informe de seguimiento de la EPT en el mundo. París: Ediciones Unesco.

UNESCO. (2016). Aportes para la enseñanza de las Ciencias Naturales. Chile: Ediciones Unesco.

Wojcicki, E., Izumi, L.T., Chang, A., Parisi, E. \& Silerman, A. (2016). Moonshots en la educación: Nuevas tecnologías y aprendizaje mixto en el aula. México: Taurus.

Velazquez, G. \& Salgado J. (2016). Innovación tecnológica: un análisis del crecimiento económico en México (20022012: proyección a 2018). Análisis Económico, 31 (78), 145-170. 